\title{
Pengaruh Kehidupan Sosial Bermusik Pengamen Terhadap Peningkatan Kreativitas
}

\author{
Anggraini Dena Putri \\ Fakultas Psikologi \\ Universitas Ahmad Dahlan Yogyakarta
}

\begin{abstract}
Abstrak
Entepreneurship atau kewirausahaan dapat menumbuhkan kreativitas dalam menciptakan suatu lapangan pekerjaan. Jiwa wirausaha yang ada biasanya datang karena beberapa faktor. Begitupun dengan Musisi Jalanan Angklung "New Kharisma" yang mencoba peruntungan dan membuka lahan pekerjaan baru yaitu musisi jalanan, menjadikan individu bisa menjadi orang-orang kreatif yang membuka lahan sehingga individu tidak harus mengemis dan meminta-minta kepada orang lain yang notabene pengemis adalah orang yang merugikan orang lain. Tetapi, Angklung "New Kharisma" membuka kesempatan baru, membuka lahan baru agar individu dapat mencari nafkah dengan cara berwirausaha dan membuka lapangan pekerjaan sendiri tanpa merepotkan orang lain. Tidak menutup kemungkinan, banyak orang yang akan membuka lahan pekerjaan baru tanpa mengandalkan orang lain ketika orang tersebut memiliki jiwa entepreneurship (kewirausahaan).
\end{abstract}

Kata Kunci: entepreneurship, musisi jalanan

\section{PENDAHULUAN}

Jiwa kewirausahaan bisa datang dari siapapun. Baik itu dari orang-orang yang berkecimpung di dunia bisnis maupun tidak. Bisa datang kapanpun, ketika individu memilih jalannya masing-masing. Pada orang-orang tertentu, jiwa kewirausahaan (entepreneurship) datang karena tuntutan beberapa hal, seperti ekonomi, sosial, dan sebagainya.

Pada grup angklung jalanan "New Kharisma", entepreneurship datang karena faktor sosial dan ekonomi. Individu tidak bergantung kepada orang lain dalam mencari pekerjaan, melainkan mencoba membuka lahan pekerjaan baru, yaitu sebagai musisi jalanan. Meskipun tidak besar hasil yang didapat, namun hasil yang diperoleh dalam sehari paling tidak dapat meringankan beban yang ditanggung. Hal ini akan menjadi motivasi bagi individu untuk meningkatkan 
daya saing dalam menciptakan pekerjaan baru, dan untuk meningkatkan kepercayaan diri.

Dapat dilihat bahwa kehidupan musisi jalanan Angklung New Kharisma memiliki jiwa entepreneurship dan dapat menjadi orang yang kreatif karena individu membuka lahan pekerjaan baru untuk kalangan kelas bawah. Individu membuktikan, tanpa mengemis pun individu bisa mendapatkan pekerjaan yang sedikit layak dan bahkan individu bekerja, tetapi juga memberikan hiburan bagi orang lain yang mendengarkan individu bermusik.

\section{PEMBAHASAN}

Kehidupan musisi jalanan Angklung "New Kharisma" memberikan warna baru bagi khazanah permusikan di Yogyakarta. Pasalnya, musisi jalanan Angklung New Kharisma membuka peruntungan dengan membuka lahan pekerjaan baru. Komunitas Angklung New Kharisma tidak menjanjikan uang yang banyak dari hasil yang individu lakukan, tetapi komunitas Angklung New Kharisma menjanjikan hal yang pasti, bahwa siapa saja bisa membuka lahan pekerjaan asal dengan tekun dan individu dapat berpikir kreatif. Inovasi juga dibutuhkan dalam membangun jiwa entepreneurship, karena setiap orang yang berusaha membuka peluang berwirausaha akan menjalani setiap tantangan dari hari ke hari. Drucker (1985) mengartikan kewirausahaan sebagai semangat, kemampuan, sikap, perilaku individu dalam menangani usaha/kegiatan yang mengarah pada upaya mencari, menciptakan, menerapkan cara kerja, teknologi, dan produk baru dengan meningkatkan efisiensi dalam rangka memberikan pelayanan yang lebih baik dan atau memperoleh keuntungan yang lebih besar. Jika tidak ada inovasi, maka individu akan kalah saing dari orang lain. Tetapi, dengan inovasi dan kreativitas yang individu miliki, individu dapat bersaing dengan orang lain.

Entrepreneurial intention atau niat kewirausahaan merupakan proses awal untuk mendirikan sebuah usaha dalam jangka waktu panjang (Lee \& Wong, 2004). Menurut Krueger (1993), niat kewirausahaan mencerminkan komitmen individu untuk memulai usaha yang baru dan merupakan isu sentral yang perlu 
diperhatikan dalam memahami proses kewirausahaan pendirian usaha baru. Tidak menutup kemungkinan individu akan mengembangkan usahanya lebih jauh dan bahkan mungkin suatu hari berpikir untuk mencari pekerjaan baru yang lebih jauh di atas. Akan tetapi, dengan profesi yang saat ini individu jalani, individu dapat membuktikan kepada masyarakat bahwa profesi sebagai musisi jalanan tidak membuat niat individu untuk mencari nafkah padam. Individu tidak mempermasalahkan tentang pekerjaan yang dijalaninya karena jiwa kewirausahaan telah menuntun individu untuk berpikir kretif dan inovatif untuk menciptakan lapangan pekerjaan baru bagi masyarakat kalangan bawah, yaitu dengan menjadi musisi jalanan.

Inovasi yang individu miliki dapat menciptakan suatu peluang baru bagi masyarakat. Individu dapat merekrut orang-orang untuk begabung bersamanya. Bergabung menciptakan suatu pekerjaan yang mungkin belum dipikirkan oleh banyak orang. Individu telah berhasil membuat pekerjaan yang sekaligus menghibur. Jika individu tidak mengandalkan kreatif dan inovasi, tentu tidak akan terbesit untuk menciptakan lahan pekerjaan sebagai musisi jalanan.

Individu memainkan alat musik, mengundang perhatian banyak orang, bernyanyi, unjuk kemampuan, menghibur banyak orang, sekaligus mencari nafkah. Jadi, ada beberapa tujuan sekaligus yang dicapai oleh para pemusik jalanan Angklung "New Kharisma" ini. Individu tidak peduli pandangan orang lain tentang apa yang individu lakukan, yang individu ingin tunjukkan adalah bisa membuka lapangan pekerjaan baru yang tidak merugikan orang lain dan tanpa bergantung dengan orang lain.

Individu bisa menciptakan lapangan pekerjaan yang diyakininya dapat membawa ke arah kesuksesan di masa depan. Individu juga telah membuat perubahan dengan mengandalkan kreativitas yang mampu individu kembangkan. Individu bisa membuka peluang usaha untuknya sendiri dan juga orang lain, sehingga menjadi bermanfaat juga untuk orang lain yang ikut bergabung bersama.

Jiwa kewirausahaan (entepreneurship) yang individu miliki, dapat membuktikan bahwa siapapun dapat menjadi orang yang berguna bagi orang lain. Individu dapat membuktikan bahwa tidak mustahil setiap orang dapat membuka 
lapangan pekerjaan. Bahkan, walau sekecil apapun. Setidaknya, kehidupan musisi jalanan Angklung New Kharisma telah memberikan warna baru untuk setiap kehidupan terutama kehidupan angklung jalanan di Yogyakarta. Musisi jalanan Angklung "New Kharisma" telah membuat perubahan baru dalam hal kreatifitas dan inovasi sehingga melahirkan suatu hal dengan membuka lapangan pekerjaan baru yang tidak banyak dipikirkan oleh kebanyakan orang. Mengandalkan feeling dan jiwa entepreneurship, individu berhasil menemnukan hal baru. Berani mengambil resiko dan menjawab tantangan yang individu hadapi di masa kini.

Semakin majunya perkembangan zaman, maka akan semakin banyak pula macam pekerjaan yang bisa diciptakan dari kalangan mana saja. Baik dari kalangan atas, kalangan menengah, maupun bawah. Individu tidak mengandalkan orang lain, hanya mengandalkan inovasi dan kreatifitas yang individu miliki untuk dapat membuat suatu hal yang mungkin akan dipandang unik di masyarakat. Hasil penelitian Tentama (2017) menunjukkan bahwa dari kalangan bawah yaitu petani memiliki motivasi berwirausaha dapat memanfaatkan limbah pertanian seperti sekam padi, jerami, dan sisa hasil panen lainnya untuk diolah menjadi produk yang memiliki nilai jual/ ekonomis seperti briket bioarang, media tanam, silase dan lain-lain (Tentama, 2016; Tentama, 2017)

\section{KESIMPULAN}

Berdasarkan data yang diperoleh, menunjukkan data bahwa musisi jalanan Angklung "New Kharisma" memiliki jiwa entepreneurship atau kewirausahaan karena individu bisa membuka lahan pekerjaan baru dengan menggunakan inovasi dan kreativitas yang individu miliki, sehingga dapat menciptakan suatu pekerjaan yang belum banyak terpikirkan oleh banyak orang, dan individu dapat merekrut orang lain di dalam pekerjaan yang individu buat. Hal ini tentu sangat bermanfaat dan dapat meringankan beban hidup orang lain.

Inovasi dan kreativitas yang individu miliki akan membentuk hal-hal baru di dalam dunia bisnis dan berbekal seni sama saja melakukan dua hal sekaligus, yaitu bekerja dan memainkan alat musik. 


\section{DAFTAR PUSTAKA}

Lee, S.H. \& Wong, P.K. (2004). An exploratory study of technopreneurial intentions: A career anchor perspective. Journal of Business Venturing, 19(1), 7-28.

Krueger, N. (1993). The impact of prior entrepre-neurial exposure on perceptions of new venture feasibility and desirability. Entrepre-neurial Theory Practice, 18(1), 5-21.

Drucker, P. F. (1985). Innovation and entrepreneurship. New York: Harper \& Row.

Tentama, F. (2016). Recycling waste of rice husk to improve entrepreneurship motivation. International Journal of Public Health Science, 5(1), 75-83.

Tentama, F. (2017). Pemberdayaan masyarakat melalui pemanfaatan limbah jerami dan sekam padi menjadi superkarbon di Kecamatan Moyudan, Sleman. Jurnal Pengabdian Pada Masyarakat. 2(2), 119-126

Tentama, F. (2017). The Effect of Waste Management Training on Entrepreneurship Motivation. Advanced Science Letters, 23(12), 1258412588(5). 